2014-04

\title{
Bedform Dynamics in a Rip Current
}

\section{Thorpe, A}

http://hdl.handle.net/10026.1/5431

10.2112/SI70-118.1

JOURNAL OF COASTAL RESEARCH

Coastal Education and Research Foundation

All content in PEARL is protected by copyright law. Author manuscripts are made available in accordance with publisher policies. Please cite only the published version using the details provided on the item record or document. In the absence of an open licence (e.g. Creative Commons), permissions for further reuse of content should be sought from the publisher or author. 


\title{
Bedform Dynamics in a Rip Current
}

\author{
Antony Thorpe, Jon Miles, Gerd Masselink, Paul Russell
}

School of Marine Science and Engineering,

University of Plymouth, Plymouth,

PL4 8AA, UK

athorpe1@plymouth.ac.uk

j.r.miles@plymouth.ac.uk

gerd.masselink@plymouth.ac.uk

p.russell@plymouth.ac.uk

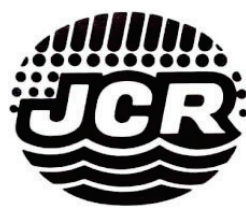

www.JCRonline.org

\section{ABSTRACT}

Thorpe, A., Miles, J., Masselink, G., Russell, P., 2014. Bedform Dynamics in a Rip Current, Proceedings $13^{\text {th }}$ International Coastal Symposium (Durban, South Africa), Journal of Coastal Research, Special Issue No. 70, pp. 700705, ISSN 0749-0208.

A Sand Ripple Profiler (SRP) was deployed in a rip channel on a dissipative sandy beach to measure bedform height $(\Delta)$, length $(\lambda)$ and migration rate $\left(M_{r}\right)$ throughout a macro-tidal cycle.

Data were collected in significant wave heights ranging from $0.5 \mathrm{~m}$ to $2.1 \mathrm{~m}$ and water depths of between $0.9 \mathrm{~m}$ and $7.4 \mathrm{~m}$. Periods when the rip current was active were identified by comparing measured cross-shore velocity $(U)$ with predicted cross-shore velocity from a bed return flow model. Rip flow was found to commence when offshore velocities reached approximately $0.1 \mathrm{~m} / \mathrm{s}$, maximum rip velocity as a 5 minute mean was $0.74 \mathrm{~m} / \mathrm{s}$.

At lower tidal elevations $(h<2.5 \mathrm{~m})$, in the strong offshore flow of the rip current megaripples were found to migrate offshore $\left(M_{r}=0-4 \mathrm{~cm} / \mathrm{min}\right)$. When migration occurred in a rip current migration rates were correlated with $U$ with the highest migration rates found in the strongest flows.

In non-rip current conditions megaripples exhibited two types of migration behaviour; (1) migrating onshore at a maximum rate of $2.1 \mathrm{~cm} / \mathrm{min}$ when $h$ was in the range of $2.5 \mathrm{~m}$ to $5 \mathrm{~m}$ and wave skewness was high and (2) megaripples were stable when mean flows and skewness were low, this occurred at higher tidal elevations when $h$ $>5 \mathrm{~m}$.

\section{ADDITIONAL INDEX WORDS: Rip Currents, Megaripples, Field Measurements, Bedform Migration}

\section{INTRODUCTION}

Rip currents are a unique feature of the nearshore zone exhibiting a channel of strong, quasi-steady, offshore-directed flow (in the order of $0.5 \mathrm{~m} / \mathrm{s}$ ) that dissects the wave dominated surfzone and dissipates beyond the breaker zone (MacMahan et al., 2005; Austin et al., 2010). Wave breaking is focused on sandbars and minimized in the rip channel; as a consequence of this water travels alongshore in feeder channels before flowing seaward within the rip neck (MacMahan et al., 2006). Rip currents are typically found at lower tidal elevations where they are associated with bar/rip morphology (Brander, 1999a).

Bedform dynamics are principally governed by the flow characteristics, and to a lesser extent grain size and the water depth in which they are situated (Allen, 1985). In the combined flows of the surfzone (waves $>$ currents), Gallagher et al. (1998) found megaripples (height $(\Delta)=0.2-0.3 \mathrm{~m}$, length $(\lambda)=2-5 \mathrm{~m}$ ) present $60 \%$ of the time (in a trough where $h=1.5-2 \mathrm{~m}$ ) during a 6 week field work campaign. The megaripples generally took the form of oval shaped holes and occurred under a wide range of wave conditions $\left(H_{s}=0.5-4 \mathrm{~m}\right)$. Onshore migration was attributed to wave skewness with typical migration rates of 0.5 $\mathrm{cm} / \mathrm{min}$ (maximum $=2.5 \mathrm{~cm} / \mathrm{min}$ ). Gallagher et al. (2003) proposed that megaripples found in the surfzone were dynamically similar to asymmetric, steady flow features present in rivers and estuaries.
In a tidal shoal of an estuary mouth (currents $>$ waves) Hoekstra et al. (2004) found megaripples $(\Delta=0.03-0.05 \mathrm{~m}, \lambda=0.6-1 \mathrm{~m})$ were consistently present and were shown to increase in wavelength with increasing mean flows and migrated in the direction of tidal flow (maximum $=0.5 \mathrm{~m} / \mathrm{s}$ ) at maximum rates of 1.1 to $1.4 \mathrm{~cm} / \mathrm{min}$.

Megaripples have also been observed to be present in rip currents (Greenwood and Davidson-Arnott, 1979; Nielsen, 1992; Aagaard et al., 1997; Brander, 1999b). Field observations suggest that in rip currents megaripples migrate offshore and are current dominated (Nielsen, 1992). Sherman et al. (1993) observed megaripples in a rip feeder channel $(V=0.4$ to $0.6 \mathrm{~m} / \mathrm{s})$ by visually measuring a pre-selected megaripple with a 'meter long aluminium comb'. They observed lunate bedforms of megaripple dimension $(\Delta=0.16 \mathrm{~m}, \lambda=1.6 \mathrm{~m})$ migrating at an average of 1.65 $\mathrm{cm} / \mathrm{min}$ in the direction of flow.

The aim of this paper is to quantify bedform dynamics, with particular focus on bedform migration, in a rip current and to investigate the processes responsible. This is achieved by comparing bedforms and their behaviour in an active rip current to that in non-rip conditions. 


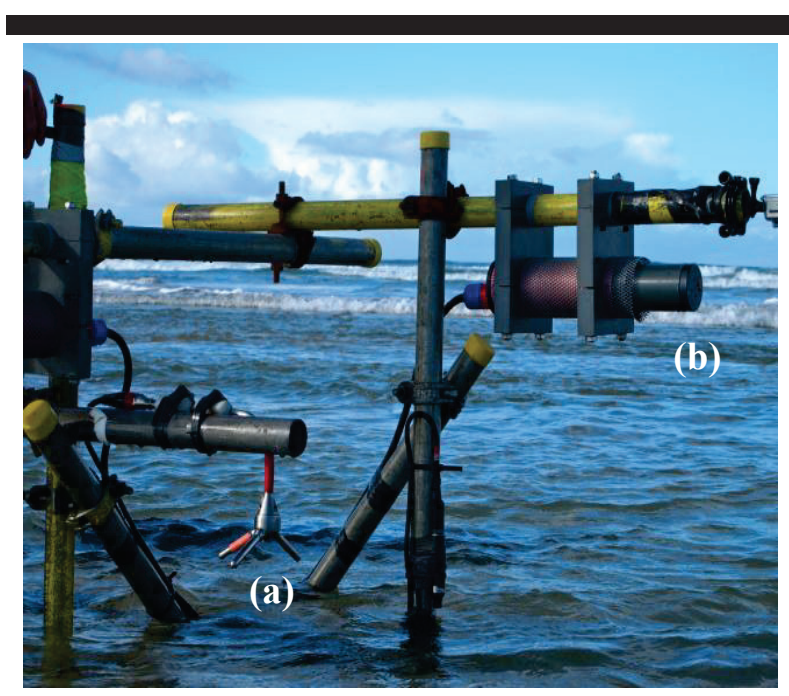

Figure 1. Mobile instrument frame and position of instruments; (a) ADV head and (b) Sand Ripple Profiler (SRP). The picture was taken at low tide in the first field experiment; at mid tide and high tide the rig is completely submerged.

\section{METHODS}

\section{Study Site}

The data in this study were collected from Perranporth on the North Cornwall Coast, UK during two separate experiments. Perranporth is a highly energetic beach with an annual significant wave height $\left(H_{s}\right)$ of $1.6 \mathrm{~m}$ and a peak period $\left(T_{p}\right)$ of $10.5 \mathrm{~s}$ (Austin et al., 2010). It faces west-northwest, is exposed to Atlantic swell and also receives locally generated wind waves. It is a macro-tidal beach with a mean spring range of $6.3 \mathrm{~m}$ and consists of medium sized sand $\left(D_{50}=0.28-0.34 \mathrm{~mm}\right)$. The beach is dissipative with pronounced low tide bar/rip morphology on a seasonal time scale (Austin et al., 2010).

During both fieldwork campaigns the beach exhibited a low tide rhythmic bar/rip system throughout its length. The rip used for the study was chosen because it offered a clearly defined channel with offshore flow dissecting the intertidal bar.

\section{Field Measurements}

Offshore wave data were collected from a wave buoy located approximately $1 \mathrm{~km}$ offshore of the study site. In-situ data were collected using a range of instruments secured to a mobile frame (Figure 1). The frame was assembled prior to deployment and carried into the rip channel at spring low tide.

The flow velocities, waves and tidal elevation in the rip channel were recorded with a Nortek Vector 3D-Acoustic Doppler Velocimeter (ADV) fitted with an internal Pressure Transducer (PT). The head of the ADV was carefully aligned to measure cross-shore and longshore flows with the sensing volume set at $0.55 \mathrm{~m}$ above the bed. The PT, used to measure wave statistics and tidal elevation was housed in the ADV casing unit with the sensor positioned at a height of $0.2 \mathrm{~m}$ above the bed. Data from the ADV, $\mathrm{PT}$ and OBS were logged autonomously at $8 \mathrm{~Hz}$ during the first experiment and $4 \mathrm{~Hz}$ in the second deployment.

A Sand Ripple Profiler (SRP) was used to measure bedform dynamics. The SRP is a pencil beam sonar scanner that collects data as a range $(R)$ and angle $(\theta)$ from the scanner. Data processing involved transforming the $(R, \theta)$ data to polar coordinates $(x=$ cross-shore distance; $z=$ distance below the scanner). The data were post-processed to produce a profile of the bed from which $\Delta, \lambda$ and $M_{r}$ were deduced. The SRP was aligned to scan in the cross-shore direction positioned $0.9 \mathrm{~m}$ above the bed, giving a footprint of approximately $2 \mathrm{~m}$ with a horizontal resolution of $14 \mathrm{~mm}$ directly below the scanner. In the second experiment a second SRP was deployed, also with a cross-shore orientation, giving a $4.4 \mathrm{~m}$ footprint. The data logger was programmed to log autonomously scanning the bed once every minute. Analysis is limited to sections of data where the acoustic scans by the SRP are unaffected by aeration in the water column from breaking waves

Bedform statistics were calculated following Masselink et al. (2007). Bedform length was found using the auto-correlation of the scan where the wavelength is twice the spatial lag corresponding to the strongest negative auto-correlation peak. For this method to work, at least half a megaripple wavelength should be captured in the scan. Bedform height was estimated as the root mean square of the bed elevation using, $\sqrt{ } 8 \sigma$, where $\sigma$ is the standard deviation of the bed level profile (Crawford and Hay, 2001). Migration rate was determined by cross-correlating scans 5 minutes apart, with the strongest positive correlation assumed to represent migration distance. This value was divided by the elapsed time to give migration rate in centimetres per minute.

\section{RESULTS}

\section{Environmental Conditions}

Data presented here were collected from six full tidal cycles (during the first field experiment) and the flood of a seventh (during a second field experiment), thus giving 13 periods when the rip current was active (accounting for flood and ebb parts of the tidal cycle). Offshore $H_{s}$ ranged from 0.5 to $1.9 \mathrm{~m}$ and peak period was between 10 to 15 seconds.

In-situ hydrodynamic parameters were calculated as 5-minute means and synchronised to periods when good SRP data were collected (Figure 2). Water depths ranged from $0.9 \mathrm{~m}$ (the depth at which the SRP was deployed) to a maximum of $7.4 \mathrm{~m}$. Wave heights $\left(H_{s}\right)$ were corrected for depth attenuation and ranged from $0.5 \mathrm{~m}$ in Tide 1 to $2.1 \mathrm{~m}$ in Tide 5 . In relatively shallow water, the rip current is active and offshore-directed flows are typically in excess of $0.3 \mathrm{~m} / \mathrm{s}$, with a maximum of $0.74 \mathrm{~m} / \mathrm{s}$ in run number 294. Mean cross-shore flows $(U)$ are close to zero in relatively deep water. Wave skewness is a measure of wave shape, with positively shaped waves having a faster onshore than offshore stroke and therefore having the potential to induce onshore sediment transport or onshore bedform migration (Gallagher et al., 1998). Normalised short-wave skewness was calculated as $S=$ $\left.<U^{3}>/<U^{2}\right\rangle^{2 / 3}$ following Elgar et al. (1988) using velocity data high-pass filtered at $0.05 \mathrm{~Hz}$. The mobility number $(\psi)$, calculated following Gallagher et al. (2003), includes both the mean and the oscillatory component of the velocity time series where; $\psi=\left(u^{2}+\right.$ $\left.v^{2}\right) /(s-1) g D$, and $s$ is the specific gravity (a ratio of sediment to water density, 2.65 for quartz sand), $g$ is acceleration due to gravity and $D$ is grain diameter. Wave skewness and mobility number exhibit a similar trend with the highest values found at lower tidal elevations and in larger waves.

To define when the rip current was active, a simple model by Masselink and Black (1995) was used to predict cross-shore velocities (as a result of bed return flow) and compared to measured cross-shore velocities (Figure 3). To consistently isolate the rip from non-rip conditions it was deemed that four consecutive observations of measured $U$ exceeding predicted $U$ 

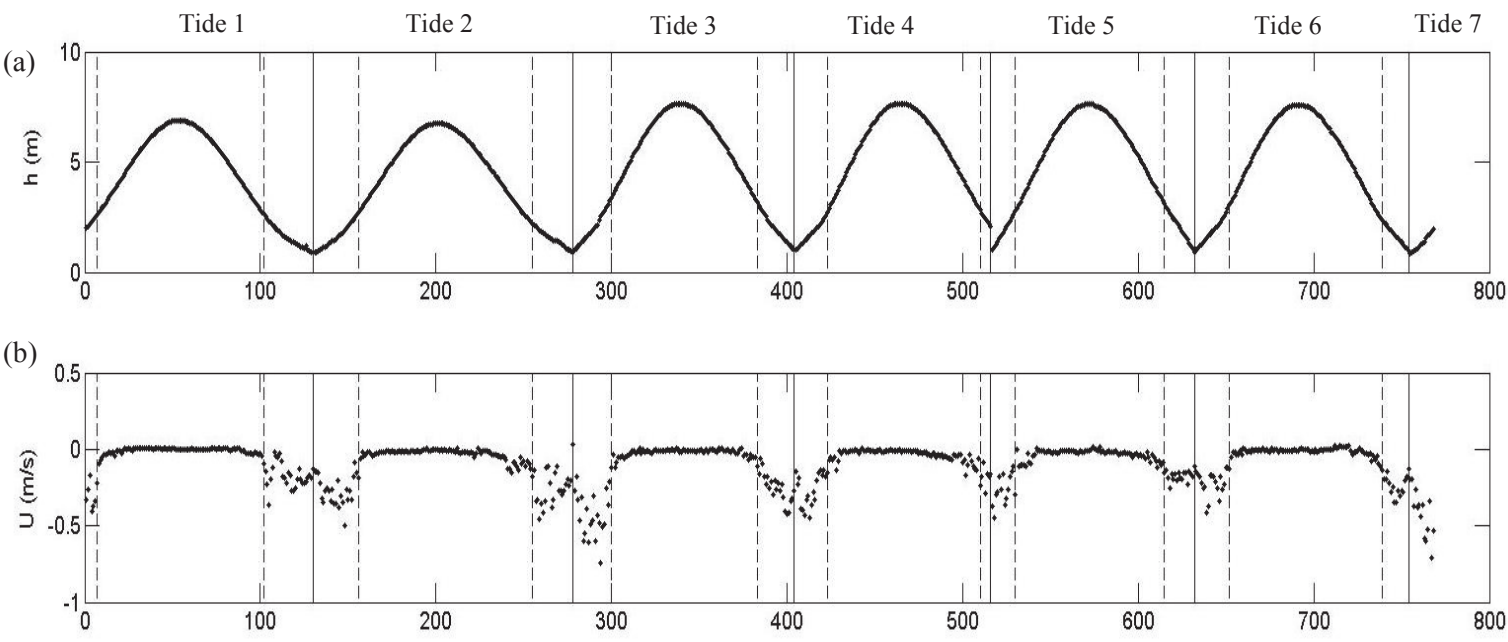

(c)

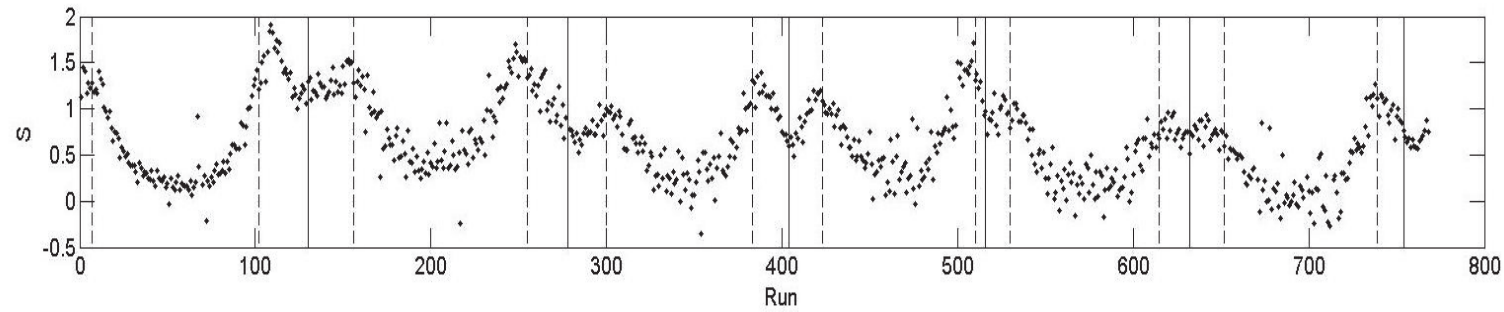

Figure 2. Hydrodynamic parameters calculated form 5 minute bursts. (a) Water depth $(h)$, (b) mean cross-shore velocity $(U)$ and (c) wave skewness $(S)$. The solid lines represent the boundaries between individual tides; the dashed lines mark the rip boundaries.

were rip current conditions, and similarly four consecutive observations where predicted $U$ exceeded measured $U$ (after a period of rip conditions) was a return to non-rip conditions.

Periods of rip current conditions are marked with a vertical dashed line in the time series plots of hydrodynamic conditions in Figure 2.

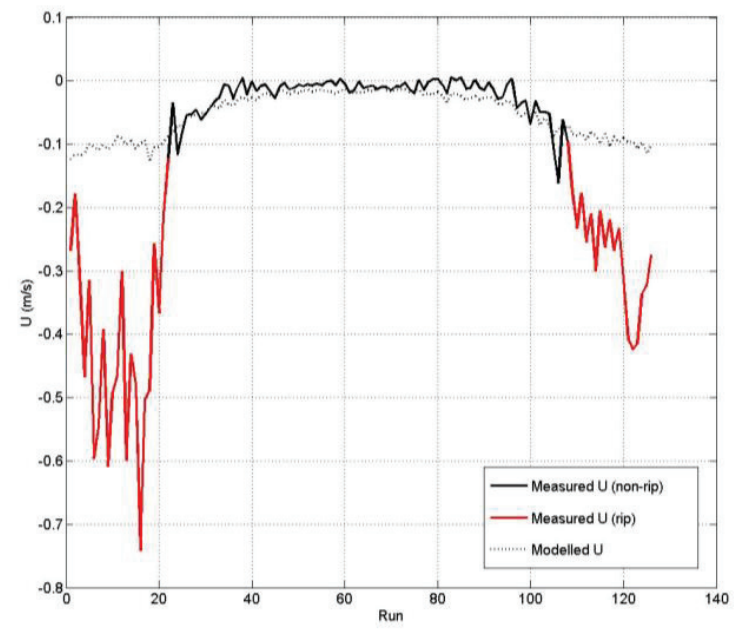

Figure 3. Rip identification. Measured $U$ against modelled $U$ with rip and non-rip conditions marked (-ve is offshore).

\section{Bedform Dimensions}

During the study bedforms of megaripple scale were found to be present in the rip channel throughout the tidal cycle (Figure 4). Bedform length and height in non-rip conditions were found to be stable with minimal change during each tide and consistent values between each tide, with $\lambda$ ranging from 0.92 to $1.35 \mathrm{~m}$ and $\Delta$ from 0.04 to $0.09 \mathrm{~m}$ (though in Tide 5, megaripple height is as high as $0.15 \mathrm{~m})$.

During rip current conditions measurements of $\lambda$ was found to be quite variable, though the observed trend is an increase in $\lambda$ compared to non-rip conditions, with $\lambda$ often of the order of $2 \mathrm{~m}$, and in some cases in excess of $3 \mathrm{~m}$. Bedform $\Delta$ in the rip current was of similar scale as in non-rip conditions, with heights ranging from 0.04 to $0.20 \mathrm{~m}$

\section{Bedform Migration}

Megaripple migration direction and speed varied over the tidal cycle, but the variation was consistent between tides. This is shown in Figure $5 a$, which was produced by collapsing 5 tides of data (from Tides 3 to 7 , all of which were of similar tidal range, allowing each data run to be averaged) onto one plot.

Typically in rip current conditions, megaripple migration was offshore at rates ranging from 0 to $4 \mathrm{~cm} / \mathrm{min}$, with the majority of offshore migration occurring at $h=<2.5 \mathrm{~m}$. Figure 6 shows an example of 60 minutes of bed data collected from within the rip current, with $h$ increasing from 0.8 to $1.7 \mathrm{~m}$ and $U$ peaking at 0.6 $\mathrm{m} / \mathrm{s}$. The average $\lambda$ and $\Delta$ were $2.9 \mathrm{~m}$ and $0.1 \mathrm{~m}$, respectively (far exceeding the typical measurements made in the non-rip conditions, where $\lambda=0.92$ to $1.35 \mathrm{~m}$ and $\Delta=0.04$ to $0.09 \mathrm{~m}$ ) and 
(a)

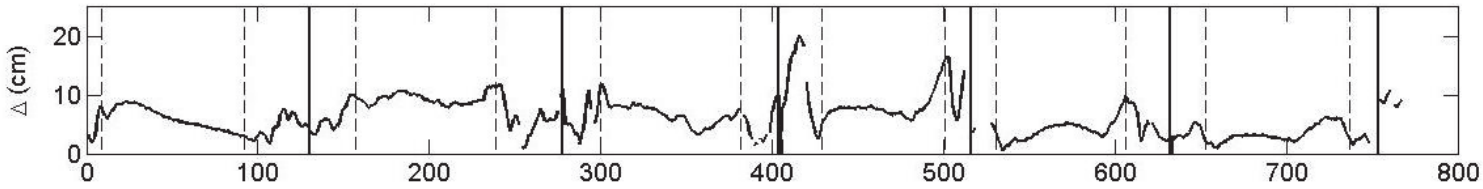

(b)

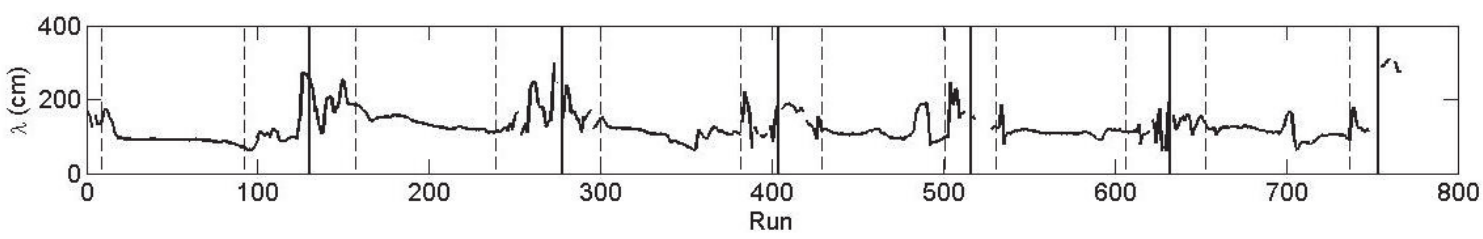

Figure 4. Time series of (a) bedform height $(\Delta)$ and (b) length $(\lambda)$. The solid lines represent the boundaries between individual tides; the dashed lines mark the rip boundaries.

average migration rate for the period was $0.75 \mathrm{~cm} / \mathrm{min}$ with a 5 minute maximum of $2.1 \mathrm{~cm} / \mathrm{min}$.

In non-rip conditions megaripples showed two different forms of migration behaviour. As tidal elevation increased $(h=2.5$ to 5 m) and mean flows became weaker as the rip became inactive the direction of migration switched to onshore at similar speeds as

(a)

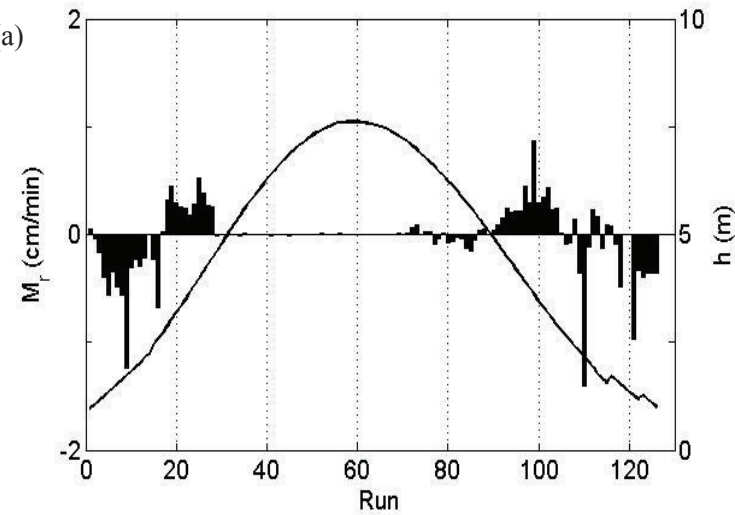

(b)

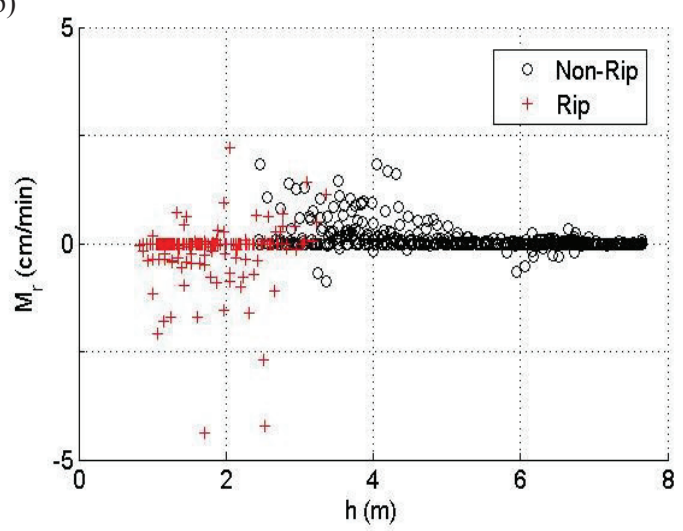

Figure 5. (a) Migration rate and direction (-ve is offshore) alongside water depth. Data from Tides 3 to 7 collapsed onto one plot. (b) Migration rate and direction as a function of water depth. the offshore migration $\left(M_{r}=0\right.$ to $\left.2.1 \mathrm{~cm} / \mathrm{min}\right)$. As the tidal elevation increased further $(h>5 \mathrm{~m})$, the megaripples remained

(a)

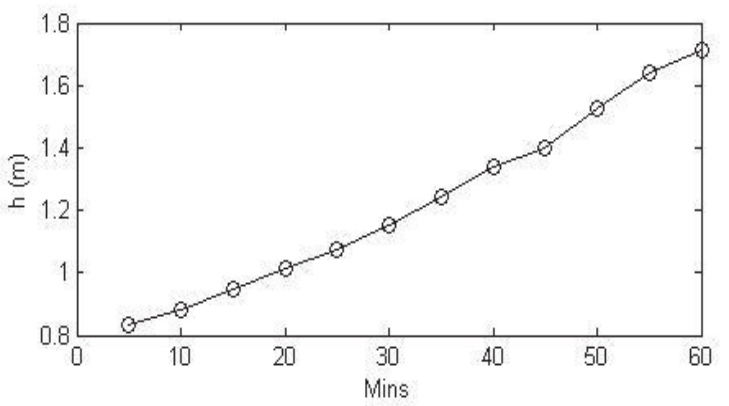

(b)

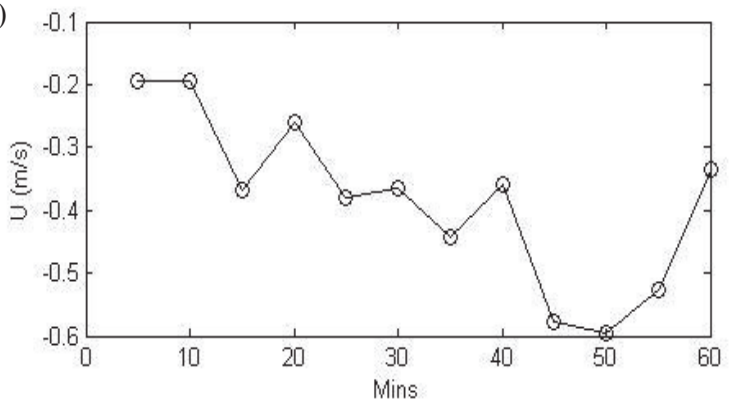

(c)

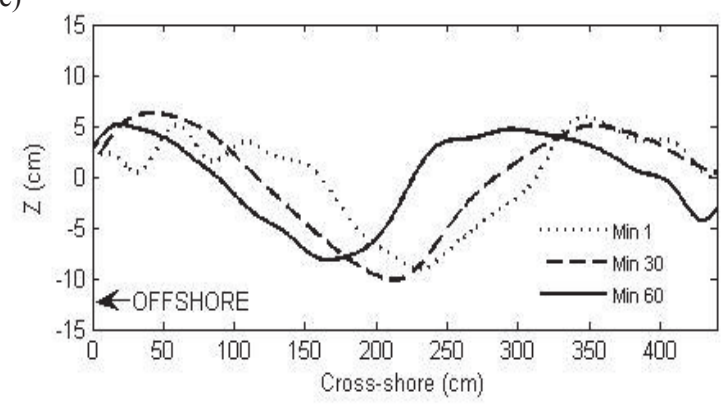

Figure 6. (a) Water depth $(h)$, (b) cross-shore velocity $(U)$ and (c) individual SRP bed scans (every 30 minutes) showing offshore megaripple migration. 
(a)

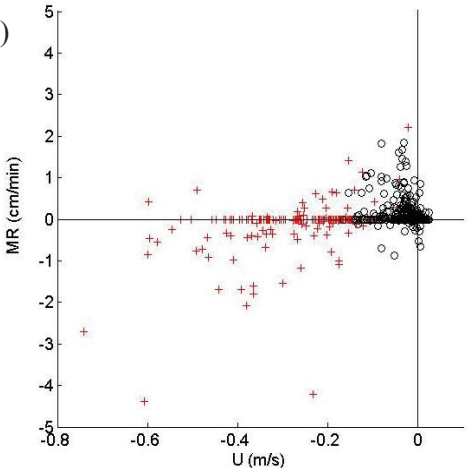

(b)

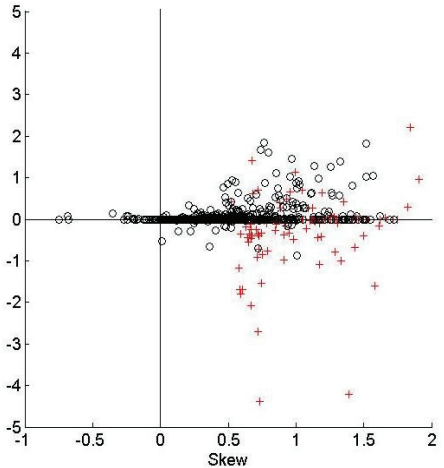

(c)

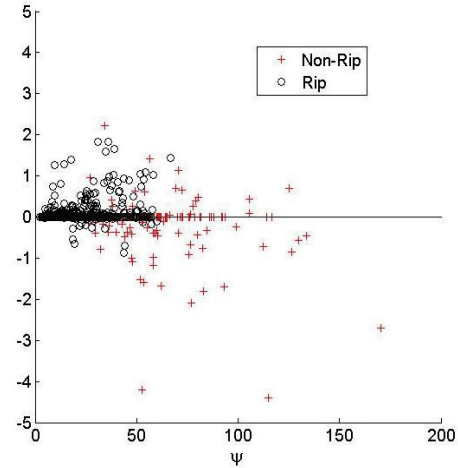

Figure 7. Hydrodynamic forcing on megaripple migration; (a) Wave skewness, (b) cross-shore velocity and (c) mobility number.

stable until the process was reversed on the flooding tide. The importance of water depth with regard to migration behaviour is shown in Figures $5 a$ and $5 b$. The partitioning of data into rip and non-rip conditions (Figure $5 b$ ) describes offshore migration in rip conditions well.

The hydrodynamic variables responsible for the different megaripple migration behaviours are investigated in Figure 6. The rip flow shows a reasonable relationship with megaripple migration. The fastest offshore migration is found in the strongest offshore flows, with little offshore migration occurring when $U=$ $<0.2 \mathrm{~m} / \mathrm{s}$ and all onshore migration taking place in weaker flows of $<0.3 \mathrm{~m} / \mathrm{s}$. At wave skewness values of below 0.5 there is no migration in any direction, whilst beyond this onshore migration rate shows an increase with increasing skewness for non-rip conditions. In rip conditions migration shows no relationship with wave skewness and there are periods of reasonably high skewness values (1.2 to 1.6$)$ and moderate flow $(0.2-0.4 \mathrm{~m} / \mathrm{s})$ when offshore migration occurs (Figure $6 b$ ). The fastest offshore migration rates are found at mobility numbers of above 50 . The majority of onshore migration was found to occur at lower

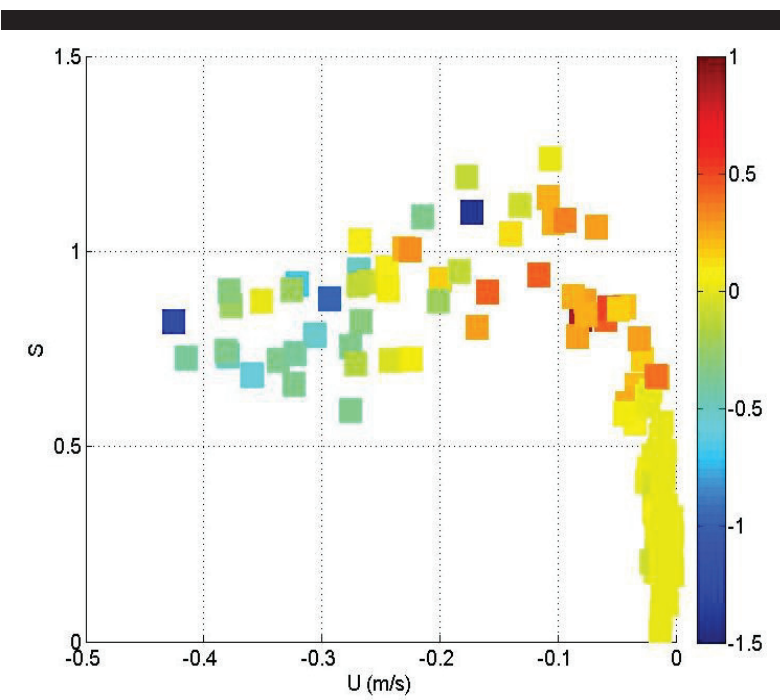

Figure 8 . Migration rate $(\mathrm{cm} / \mathrm{min})$ and direction (represented by the colour bar; 'cool' colours indicating offshore migration) as a function of cross-shore velocity and wave skewness. Data from Tides 3 to 7 . mobility numbers.

The combined forcing of megaripple migration by mean offshore flows and wave skewness is investigated in Figure 8. Following figure $5 a$, the same method has been applied for $U$ and $S$. There are three well defined parameter spaces within the figure with low $S$ and weak $U$ resulting in a stable bed. Weak $U$ and high $S$ result in onshore migration and strong offshore directed $U$ and low $S$ resulting in offshore migration.

\section{DISCUSSION}

Bedforms of megaripple scale were found to be consistently present in rip currents in the data collected, confirming field observations by Greenwood and Davidson-Arnott, (1979), Aagaard et al. (1997) and Brander (1999b). The megaripples in the rip were, at times, over twice the length of the bedforms in non-rip conditions, suggesting an increase in wavelength was the result of conditions becoming increasingly current dominated, agreeing with observations made by Hoekstra et al. (2004) in a tidal inlet.

The partitioning of the data into rip and non-rip conditions based on a comparison with predicted offshore flows works well as a means of identifying rip flow, with the boundary between rip and non-rip conditions closely matching the change in migration direction. Rip flow ceased at velocities weaker than $0.1 \mathrm{~m} / \mathrm{s}$ but this value would possibly depend on the hydrodynamic forcing of the rip and the scale of the controlling morphology.

Bedform migration in a rip current was found to undergo three phases over an entire tidal cycle; offshore migration in the strong offshore flows of the rip, onshore migration when skewness was high and mean flows were low and stable around high tide $(h>5$ $\mathrm{m})$ when both mean flows and skewness was low.

Though offshore migration did not always occur in a rip the migration rate was positively correlated to the rip velocity, supporting the assertion by Nielsen (1992) that bedforms in a rip current are current dominated. The rates of migration in a rip current recorded in this study ( 0 to $4 \mathrm{~cm} / \mathrm{min}$ ) compare favourably to measurements made by Sherman et al. (1993) in a feeder channel of an average of $1.35 \mathrm{~cm} / \mathrm{min}$ with similar mean flows.

If the waves are positively skewed the onshore stroke of the wave is stronger than the offshore stroke resulting in net onshore sediment transport. Gallagher et al. (2003) proposed this may result in onshore migration of bedforms. In the data presented here, skewness values are low in deep water, and peak when $h=2$ to $3 \mathrm{~m}$, coinciding with periods of onshore migration. Migration rates of megaripples in non-rip conditions increase with increasing 
skewness. Wave skewness and strong offshore-directed mean flows peak at similar times and the clear change in migration direction at $h=\sim 2.5 \mathrm{~m}$ suggests that they compete for control over megaripple migration and there is a fine balance between which is the dominant forcing. However, the fact that offshore migration is shown to take place in relatively high skewness values suggests that mean flows can dominate even if skewness is high.

The apparent change in hydrodynamic forcing over the tidal cycle is not possible to describe with a single parameter. The form of mobility number used by Gallagher et al.(2003) was chosen as it includes both an oscillatory and mean flow component. It shows a reasonable relationship with offshore migration, though no correlation with onshore migration. This may be because skewness is a measure of wave shape and not oscillatory flow.

\section{CONCLUSION}

New measurements within a rip channel have found bedform migration rate and direction to be dependent on the occurrence of offshore directed flows of the rip current, wave skewness and water depth. In an active rip current $(U=0.1$ to $0.74 \mathrm{~m} / \mathrm{s})$ bedforms were found to migrate offshore at rates of 0 to $4 \mathrm{~cm} / \mathrm{min}$, with migration rates showing an approximately linear relationship with rip velocity. In non-rip conditions bedforms were observed to migrate onshore in water of intermediate depths $(h=2.5$ to $5 \mathrm{~m})$ and when skewness was high $(>0.5)$. When $h>5 \mathrm{~m}$ and both skewness and mean flows were low the bed was stable.

\section{ACKNOWLEDGEMENTS}

This work is part of the first author's $\mathrm{PhD}$. We would like to acknowledge the Natural Environment Research Council (NERC) for their funding of the PhD studentship (ref no: NE/I528550/1).

We would also like to thank the DRIBS (Dynamics of Rip Currents and Implications for Beach Safety) project (grant ref no: $\mathrm{NE} / \mathrm{H} 004262 / 1)$ for providing technical assistance and use of the infra-structure in place for their fieldwork.

\section{LITERATURE CITED}

Aagaard, T., Greenwood, B.,Nielsen, J., 1997. Mean currents and sediment transport in a rip channel. Marine Geology, 140, 2545.

Allen, J. R. L., 1985. Principles of Physical Sedimentology. London: George Allen,Unwin Ltd.

Austin, M., Scott, T., Brown, J., Brown, J., MacMahan, J., Masselink, G.,Russell, P. 2010. Temporal observations of rip current circulation on a macro-tidal beach. Continental Shelf Research, 30, 1149-1165.

Brander, R. W., 1999a. Field observations on the morphodynamic evolution of a low-energy rip current system. Marine Geology, 157, 199-217.

Brander, R. W., 1999b. Sediment Transport in Low Energy Rip Current Systems. Journal of Coastal Research, 15, 839-849.

Crawford, A.,Hay, A. 2001. Linear transition ripple migration and wave orbital velcoity skewness: Observations. Journal of Geophysical Research, 106, 14133-14128.

Elgar, S., Guza, R. T.,Freilich, M. H., 1988. Eulerian measurements of horizontal accelerations in shoaling gravity waves. Journal of Geophysical Research: Oceans, 93, 92619269.

Gallagher, E. L., Elgar, S.,Thornton, E. B., 1998. Megaripple migration in a natural surf zone. Nature, 394, 165-168.

Gallagher, E. L., Thornton, E. B.,Stanton, T. P. 2003. Sand bed roughness in the nearshore. Journal of Geophysical Research: Oceans, 108, 3039.
Greenwood, B.,Davidson-Arnott, R. G. D., 1979. Sedimentation and equilibrium in wave-formed bars: a review and case study. Canadian Journal of Earth Sciences, 16, 312-332.

Hoekstra, P., Bell, P., van Santen, P., Roode, N., Levoy, F.,Whitehouse, R., 2004. Bedform migration and bedload transport on an intertidal shoal. Continental Shelf Research, 24, 1249-1269.

MacMahan, J. H., Thornton, E. B.,Reniers, A. J. H. M., 2006. Rip current review. Coastal Engineering, 53, 191-208.

MacMahan, J. H., Thornton, E. B., Stanton, T. P.,Reniers, A. J. H. M. 2005. RIPEX: Observations of a rip current system. Marine Geology, 218, 113-134.

Masselink, G., Austin, M., O'Hare, T.,Russell, P., 2007. Geometry and dynamics of wave ripples on thearshore of a coarse sandy beach. Geophysical Research Letters, 112

Masselink, G.,Black, K.P., 1995. Magnitude and cross-shore distribution of bed return flow measured on natural beaches. Coastal Engineering, 25, 165-190.

Nielsen, P., 1992. Coastal bottom boundary layers and sediment transport. Advanced series on ocean engineering. London: World Scientific.

Sherman, D. J., Short, A.D.,Takeda, I., 1993. Sediment MixingDepth and Bedform Migration in Rip channels. Journal of Coastal Research, 15, 39-48. 